\title{
A Comparative Study of Laparoscopic versus Open Pancreaticoduodenectomy for Ampulla of Vater Carcinoma
}

\author{
Daegwang Yoo, Ki Byung Song *(D, Jong Woo Lee, Kyungyeon Hwang, Sarang Hong, \\ Dakyum Shin $\mathbb{D}$, Dae Wook Hwang, Jae Hoon Lee, Woohyung Lee $\mathbb{D}$, Jaewoo Kwon $\mathbb{D}^{\text {, }}$ \\ Yejong Park $\mathbb{B}$, Eunsung Jun and Song Cheol Kim
}

\author{
Division of Hepatobiliary and Pancreatic Surgery, Department of Surgery, Asan Medical Center, University of \\ Ulsan College of Medicine, Seoul 05505, Korea; yoodaegwang@naver.com (D.Y.); \\ hy_thename@hanmail.net (J.W.L.); hkyz84@gmail.com (K.H.); 8thofnovember@hanmail.net (S.H.); \\ gracedkshin@gmail.com (D.S.); drdwhwang@gmail.com (D.W.H.); gooddr23@naver.com (J.H.L.); \\ ywhnet@gmail.com (W.L.); skunlvup@naver.com (J.K.); blackpig856@gmail.com (Y.P.); \\ eunsungjun@amc.seoul.kr (E.J.); drksc@amc.seoul.kr (S.C.K.) \\ * Correspondence: mtsong21c@naver.com or mtsong21c@amc.seoul.kr; Tel.: +82-2-3010-1520
}

Received: 23 June 2020; Accepted: 9 July 2020; Published: 13 July 2020

\begin{abstract}
Several studies have compared laparoscopic pancreaticoduodenectomy (LPD) and open pancreaticoduodenectomy (OPD) in patients with periampullary carcinoma; however, only a few studies have made such a comparison on patients with ampulla of Vater cancer (AVC). We compared the perioperative and oncologic outcomes between LPD and OPD in patients with AVC using propensity-score-matched analysis. A total of 359 patients underwent PD due to AVC during the study period (76 LPD, 283 OPD). After propensity score matching, the LPD group showed significantly longer operation time than did the OPD group (400.2 vs. $344.6 \mathrm{~min}, p<0.001$ ). Nevertheless, the LPD group had fewer painkiller administrations (8.3 vs. 11.1, $p<0.049$ ), fewer Grade II or more severe postoperative complications $(15.9 \%$ vs. $34.8 \%, p=0.012)$, and shorter postoperative hospital stays (13.7 vs. 17.3 days, $p=0.048)$, compared with the OPD group. There was no significant difference in recurrence-free outcomes and overall survival between the two groups ( $p=0.754$ and 0.768 , respectively). Compared with OPD, LPD for AVC had comparative oncologic outcomes with less pain, less postoperative morbidity, and shorter hospital stays. LPD may serve as a promising alternative to OPD in patients with AVC.
\end{abstract}

Keywords: ampulla of Vater; cancer; laparoscopy; pancreaticoduodenectomy; propensity score

\section{Introduction}

Ampulla of Vater cancer (AVC) is defined as a malignancy that arises within the ampullary complex, distal to the confluence of the distal common bile duct and the pancreatic duct. AVC is a rare malignancy and accounts for $0.2 \%$ of all digestive malignancies, with an annual incidence of $0.4-0.5$ cases per 100,000 people per year [1,2].

Pancreaticoduodenectomy (PD) remains the mainstay curative treatment for patients with AVC, and owing to improvements in the technology and techniques of minimally invasive surgery, laparoscopic pancreaticoduodenectomy (LPD) is being performed more frequently in large volume hospitals. Following its first description by Gagner et al. in 1994 [3], LPD has been evaluated for its adequacy and feasibility in numerous studies [4-14]. Although LPD requires complex dissection and reconstruction, it offers acceptable perioperative and oncologic outcomes [4-7,9]. 
LPD is relatively easy to apply in AVC because AVC has little multivisceral invasion and a small tumor size. However, only a few reports have solely evaluated LPD for AVC $[15,16]$, which included a small number of patients and lacked adequate matched groups that received open PD (OPD) for comparison [15]. In the present study, we retrospectively reviewed the oncologic and perioperative outcomes of AVC following LPD and OPD performed at a single large volume center and performed propensity score matching in order to compare the two surgical methods in terms of oncologic adequacy and perioperative outcomes.

\section{Methods}

\subsection{Patient Database}

Data from all patients who had AVC and underwent PD between August 2011 and December 2017 at Asan Medical Center (Seoul, Korea) were retrospectively reviewed. Patients were grouped according to surgical approach (LPD or OPD), and details of their demographics, surgical variables, postoperative outcomes, and postoperative follow-up data were collected. The following clinical, pathologic, and surgical data were collected: age at operation; sex; body mass index (BMI); American Society of Anesthesiologists (ASA) score [17]; comorbidities; preoperative biliary or pancreatic drainage; preoperative laboratory data; concurrent resection of other organs; operative time; transfusion; number of total harvested lymph nodes; tumor size; tumor differentiation; perineural invasion; lymphovascular invasion; resection margin status; tumor, node, and metastasis (TNM) stages (American Joint Committee on Cancer, 7th edition) [18]; length of hospital stay; postoperative complications; use of adjuvant therapy; recurrence; and overall survival. As for postoperative follow-up data, the duration of survival after surgery was measured from the time of surgery until death or the last visit to the outpatient department; postoperative pancreatic fistula (POPF) was defined and graded according to the recommendations of the International Study Group on Pancreatic Fistula [19]; and a clinically relevant POPF (CR-POPF) was defined as a grade B or C POPF. Postoperative complications were classified using the Clavien-Dindo classification system [20], and clinically relevant postoperative complications were defined as grade II or more severe complications. The study was approved by the Institutional Review Board of Asan Medical Center (approval number: 2018-0845).

\subsection{Operative Procedure}

The patients were informed about the advantages and disadvantages of both LPD and OPD. We presented earlier postoperative recovery and shorter operative time as the primary advantages of LPD and OPD, respectively. Whether to undergo LPD or OPD was decided by the patient and the surgeon's preference, after discussion of both approaches. All patients provided written informed consent for their operations. Surgical procedures were mostly similar between LPD and OPD and were performed as previously described $[4,5]$.

\subsection{Statistical Analysis}

Clinicopathologic characteristics and operative outcomes were compared between the LPD and OPD groups prior to matching. Continuous variables were analyzed using Student's $t$-test or Mann-Whitney $\mathrm{U}$ test and are presented as mean \pm standard deviation (SD). Categorical variables were analyzed using the $\chi^{2}$ test or Fisher's exact test and are presented as numbers and percentages of patients. Survival rates and comparisons were estimated by the Kaplan-Meier survival curves and the log-rank test. Differences with $p$ values $\leq 0.05$ were considered statistically significant.

Matching between the LPD and OPD patients was performed by estimating a propensity score for each patient and matching the patients from the two groups in a 1:1 ratio. To estimate the propensity score, we used a logistic regression model using 14 variables, which were clinicopathologic characteristics that may affect perioperative and oncologic outcomes [21-23]. The variables consisted of 5 continuous variables (age (years), BMI $\left(\mathrm{kg} / \mathrm{m}^{2}\right)$, Charlson comorbidity index, tumor size $(\mathrm{cm})$, 
and preoperative carcinoembryonic antigen (CEA) level) and 9 categorical variables (sex (male or female), ASA score (class I to V), preoperative biliary or pancreatic drainage, tumor differentiation (well, moderately, or poorly differentiated), perineural invasion, lymphovascular invasion, $\mathrm{T}$ stage (T1 to T4), N stage (N0 to N1) (American Joint Committee on Cancer, 7th edition) [18], and preoperative carbohydrate antigen 19-9 (CA 19-9) level) [24].

Propensity score was estimated with LPD as the dependent variable by multiple logistic regression analysis [25-27]. A full nonparsimonious model was developed that included all the abovementioned variables and the interaction terms between variables. Model discrimination was assessed with $C$ statistics, and model calibration was assessed with Hosmer-Lemeshow statistics $\left(\chi^{2}=6.1411\right.$, degree of freedom $=8, p=0.6314$ ). Propensity score matching was performed by Greedy matching using a caliper of 0.2 standard deviations of the logit of the propensity score. The absolute standardized differences were used to diagnose the balance after matching. All absolute standardized differences after matching were less than 0.1 . After propensity score matching, continuous variables are presented as mean \pm SD and were analyzed using a paired $t$-test. Categorical variables were analyzed using McNemar's test or the marginal homogeneity test and are presented as numbers and percentages of patients. Survival rates and comparisons were estimated by Kaplan-Meier survival curves and Cox regression models, with robust standard errors that accounted for the clustering of matched pairs. All statistical analyses were carried out in IBM SPSS version 24.0 (IBM Corp., Armonk, NY, USA) and SAS version 9.4 (SAS Institute, Cary, NC, USA).

\section{Results}

\subsection{Comparative Analysis between the LPD and OPD Groups-Unmatched Patients}

A total of 359 patients with AVC underwent PD during the study period, of whom 76 and 283 received LPD and OPD, respectively. The demographic characteristics and preoperative factors of all unmatched patients are listed in Table 1 . There were no statistically significant differences in terms of sex, BMI, ASA score, Charlson comorbidity index, or the rate of preoperative biliary (or pancreatic) drainage between the two groups.

Table 1. Demographic characteristics and preoperative factors of all unmatched patients who underwent laparoscopic pancreaticoduodenectomy (LPD) or open pancreaticoduodenectomy (OPD).

\begin{tabular}{|c|c|c|c|}
\hline \multirow{2}{*}{ Characteristics } & LPD & OPD & $p$-Value \\
\hline & $(n=76)$ & $(n=283)$ & \\
\hline Age, years $($ mean $\pm S D)$ & $62.5 \pm 10.3$ & $63.7 \pm 8.8$ & 0.295 \\
\hline Sex, $n(\%)$ & & & 0.336 \\
\hline Female & $38(50.0)$ & $124(43.8)$ & \\
\hline Male & $38(50.0)$ & $159(56.2)$ & \\
\hline $\mathrm{BMI}, \mathrm{kg} / \mathrm{m}^{2}($ mean $\pm \mathrm{SD})$ & $23.0 \pm 2.8$ & $23.6 \pm 2.8$ & 0.086 \\
\hline ASA score, $n(\%)$ & & & 0.398 \\
\hline Class I & $7(9.2)$ & $28(9.9)$ & \\
\hline Class II & $60(78.9)$ & $235(83.0)$ & \\
\hline Class $\geq$ III & $9(11.8)$ & $20(7.1)$ & \\
\hline Charlson comorbidity index (mean \pm SD) & $2.2 \pm 1.3$ & $2.3 \pm 1.3$ & 0.447 \\
\hline Preoperative biliary/pancreatic drainage, $n(\%)$ & & & 0.827 \\
\hline No & $20(26.3)$ & $71(25.1)$ & \\
\hline Yes & $56(73.7)$ & $212(74.9)$ & \\
\hline
\end{tabular}

BMI, body mass index; ASA, American Society of Anesthesiologists.

Table 2 shows the pathologic findings of the two groups. The LPD group had a significantly lower rate of perineural invasion than did the OPD group $(11.8 \%$ vs. $26.5 \%, p=0.007)$. T stages were also significantly different between the two groups $(p=0.038)$. 
Table 2. Pathologic findings of all unmatched patients who underwent laparoscopic pancreaticoduodenectomy (LPD) or open pancreaticoduodenectomy (OPD).

\begin{tabular}{cccc}
\hline Characteristics & LPD & OPD & $p$-Value \\
\cline { 2 - 4 } & $(n=76)$ & $(n=283)$ & \\
\hline Tumor size, cm (mean \pm SD) & $1.8 \pm 1.0$ & $2.0 \pm 0.9$ & 0.295 \\
Differentiation, $n(\%)$ & $27(35.5)$ & $79(28.2)$ & 0.189 \\
Well & $45(59.2)$ & $169(60.4)$ & \\
Moderate & $4(5.3)$ & $32(11.4)$ & \\
Poor & & & 0.007 \\
No & $67(88.2)$ & $208(73.5)$ & \\
Yes & $9(11.8)$ & $75(26.5)$ & \\
Perineural invasion, $n(\%)$ & $41(53.9)$ & $147(51.9)$ & \\
No & $35(46.1)$ & $136(48.1)$ & \\
Yes & & & \\
Lymphovascular invasion, $n(\%)$ & $29(38.2)$ & $63(22.3)$ & \\
T1 & $26(34.2)$ & $129(45.6)$ & \\
T2 & $18(23.7)$ & $82(29.0)$ & \\
T3 & $3(3.9)$ & $9(3.2)$ & \\
T4 & & & \\
AJCC 7th stage, $n(\%)$ & $55(72.4)$ & $187(66.3)$ & \\
N0 & $21(27.6)$ & $95(33.7)$ & \\
N1 & & & \\
\hline
\end{tabular}

AJCC, American Joint Committee on Cancer.

Table 3 shows the operative outcomes and complications of unmatched patients. The LPD group had a significantly longer operation time ( $371 \mathrm{vs.} 317 \mathrm{~min}, \mathrm{p}<0.001)$ and a smaller number of total harvested lymph nodes (14 vs. $16.6, p=0.003$ ). As for postoperative outcomes, the LPD group had a significantly lower rate of CR-POPF (9.2\% vs. $20.1 \%, p=0.027)$, a lower rate of Grade II or more severe postoperative complications $(15.8 \%$ vs. $30.0 \%, p=0.012)$, and shorter hospital stays (13.6 vs. 18.8 days, $p=0.02$ ). There was no significant difference in Kaplan-Meier curves of recurrence-free survival $(p=0.536)$ and overall survival between the two groups $(p=0.222)$ (Figure 1$)$.

\section{a}

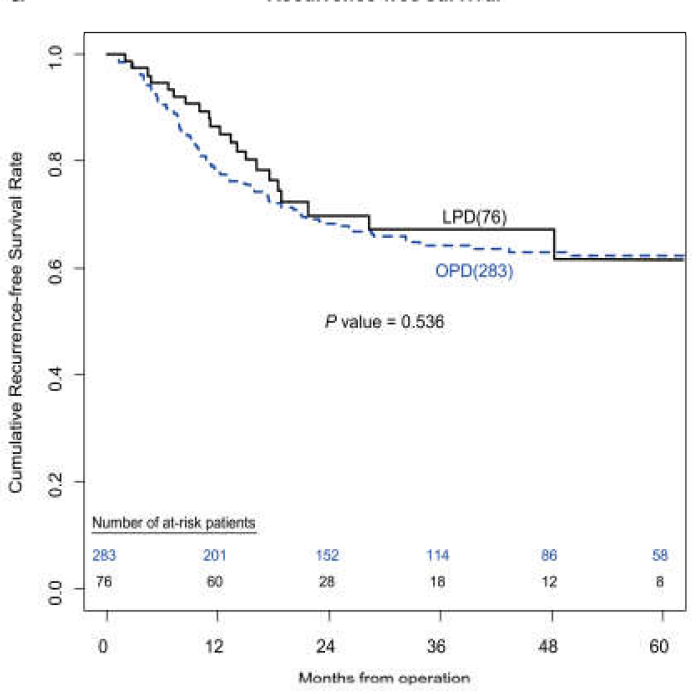

b

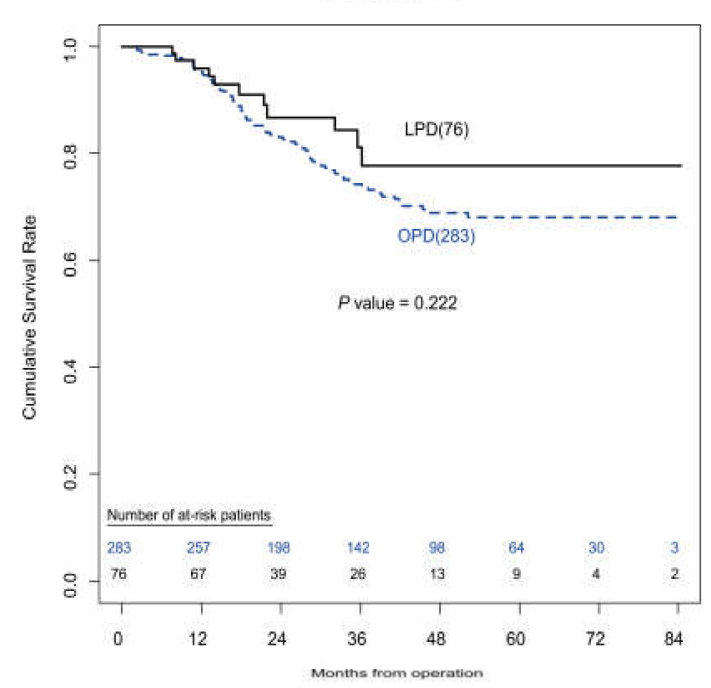

Figure 1. (a) Kaplan-Meier curves of recurrence-free survival after surgery in unmatched patients who underwent OPD or LPD. (b) Kaplan-Meier curves of overall survival after surgery in unmatched patients who underwent OPD or LPD. 
Table 3. Perioperative outcomes of all unmatched patients who underwent laparoscopic pancreaticoduodenectomy (LPD) or open pancreaticoduodenectomy (OPD).

\begin{tabular}{|c|c|c|c|}
\hline \multirow{2}{*}{ Characteristics } & LPD & OPD & $p$-Value \\
\hline & $(n=76)$ & $(n=283)$ & \\
\hline Operative time, $\min ($ mean $\pm \mathrm{SD})$ & $371.0 \pm 90.6$ & $317.0 \pm 82.4$ & $<0.001$ \\
\hline Transfusion, $n(\%)$ & & & 0.343 \\
\hline No & $67(88.2)$ & 237 (83.7) & \\
\hline Yes & $9(11.8)$ & $46(16.3)$ & \\
\hline Number of harvested LN, $n($ mean $\pm \mathrm{SD})$ & $14.0 \pm 6.1$ & $16.6 \pm 8.0$ & 0.003 \\
\hline Resection margin status, $n(\%)$ & & & $>0.999$ \\
\hline Negative (R0) & $75(98.7)$ & 279 (98.6) & \\
\hline Positive (R1) & $1(1.3)$ & $4(1.4)$ & \\
\hline Length of hospital stay, days (mean \pm SD) & $13.6 \pm 10.3$ & $18.8 \pm 18.4$ & 0.02 \\
\hline CR-POPF, $n(\%)$ & & & 0.027 \\
\hline No & $69(90.8)$ & $226(79.9)$ & \\
\hline Yes & $7(9.2)$ & $57(20.1)$ & \\
\hline Delayed gastric emptying, $n(\%)$ & & & 0.453 \\
\hline No & $72(94.7)$ & $261(92.2)$ & \\
\hline Yes & $4(5.3)$ & $22(7.8)$ & \\
\hline Complications, $n(\%)$ & & & 0.013 \\
\hline Grade 0-I & $64(84.2)$ & $198(70.0)$ & \\
\hline$\geq$ Grade II & $12(15.8)$ & $85(30.0)$ & \\
\hline Readmission due to complication, $n(\%)$ & & & 0.093 \\
\hline No & $65(85.5)$ & $260(91.9)$ & \\
\hline Yes & $11(14.5)$ & $23(8.1)$ & \\
\hline
\end{tabular}

SD, standard deviation; LN, lymph node; CR-POPF, clinically relevant postoperative pancreatic fistula.

\subsection{Comparative Analysis between the LPD and OPD Groups-Propensity-Score-Matched Patients}

To reduce the effect of selection bias, propensity score matching was performed using the selected baseline characteristics. As a result, 69 patients from each group were matched. The two matched groups did not show any statistically significant differences in baseline characteristics and pathologic findings (Table 4). Table 5 shows the results of operative outcomes and complications of the propensity-score-matched patients. The LPD group had significantly longer operation time ( 400.2 vs. $344.6 \mathrm{~min}, p<0.001$ ), fewer painkiller administrations ( 8.3 vs. 11.1, $p=0.049$ ), and a shorter duration of postoperative hospital stays ( 13.7 vs. 17.3 days, $p=0.002)$. In addition, CR-POPF ( $8.7 \%$ vs. $21.7 \%, p=0.029)$ and Grade II or more severe postoperative complications ( $15.9 \%$ vs. $34.8 \%, p=0.012)$ were less common in the LPD group. There were no significant differences in recurrence-free survival $(p=0.754)$ and overall survival between the two groups $(p=0.768)$ (Figure 2$).$

Table 4. Comparison of baseline characteristics and pathologic findings between laparoscopic pancreaticoduodenectomy (LPD) and open pancreaticoduodenectomy (OPD) groups after propensity score matching.

\begin{tabular}{cccc}
\hline Characteristics & Matched LPD & Matched OPD & $p$-Value \\
\cline { 2 - 3 } & $(\boldsymbol{n = 6 9 )}$ & $\mathbf{( n = 6 9 )}$ & \\
\hline Age, years (mean \pm SD) & $62.8 \pm 10.1$ & $63.2 \pm 8.6$ & 0.806 \\
Sex, $n(\%)$ & & & 0.48 \\
Female & $35(50.7)$ & $31(44.9)$ & \\
Male & $34(49.3)$ & $38(55.1)$ & \\
BMI, kg/m (mean \pm SD) $_{\text {ASA score, } n(\%)}$ & $23.1 \pm 2.7$ & $23.5 \pm 3.3$ & 0.367 \\
Class I & & & 0.8 \\
Class II & $5(7.3)$ & $7(10.1)$ & \\
Class $\geq$ III & $56(81.2)$ & $55(79.7)$ & \\
\hline
\end{tabular}


Table 4. Cont.

\begin{tabular}{|c|c|c|c|}
\hline \multirow{2}{*}{ Characteristics } & Matched LPD & Matched OPD & $p$-Value \\
\hline & $(n=69)$ & $(n=69)$ & \\
\hline Charlson comorbidity index (mean $\pm \mathrm{SD})$ & $2.2 \pm 1.3$ & $2.3 \pm 1.1$ & 0.667 \\
\hline Preoperative biliary / pancreatic drainage, $n(\%)$ & & & $>0.999$ \\
\hline No & $18(26.1)$ & $18(26.1)$ & \\
\hline Yes & $51(73.9)$ & $51(73.9)$ & \\
\hline Tumor size, cm (mean \pm SD) & $1.9 \pm 1.0$ & $1.8 \pm 1.0$ & 0.551 \\
\hline Differentiation, $n(\%)$ & & & 0.69 \\
\hline Well & $26(37.7)$ & $29(42.0)$ & \\
\hline Moderate & $39(56.5)$ & $38(55.1)$ & \\
\hline Poor & $4(5.8)$ & $2(2.9)$ & \\
\hline Perineural invasion, $n(\%)$ & & & 0.739 \\
\hline No & $62(89.9)$ & $61(88.4)$ & \\
\hline Yes & $7(10.1)$ & $8(11.6)$ & \\
\hline Lymphovascular invasion, $n(\%)$ & & & 0.369 \\
\hline No & $39(56.5)$ & $44(63.8)$ & \\
\hline Yes & $30(43.5)$ & $25(36.2)$ & \\
\hline AJCC 7th T stage, $n(\%)$ & & & 0.836 \\
\hline $\mathrm{T} 1$ & $26(37.7)$ & $31(44.9)$ & \\
\hline $\mathrm{T} 2$ & $25(32.2)$ & $22(31.9)$ & \\
\hline T3 & $16(23.2)$ & $14(20.3)$ & \\
\hline $\mathrm{T} 4$ & $2(2.9)$ & $2(2.9)$ & \\
\hline AJCC 7th N stage, $n(\%)$ & & & 0.532 \\
\hline No & $51(73.9)$ & $54(78.3)$ & \\
\hline N1 & $18(26.1)$ & $15(21.7)$ & \\
\hline CA $19-9, \mathrm{U} / \mathrm{ml}$ & & & 0.647 \\
\hline$\leq 35$ & $52(75.4)$ & $53(76.8)$ & \\
\hline $35 \sim 200$ & $13(18.8)$ & $13(18.8)$ & \\
\hline $200 \sim 1000$ & $3(4.4)$ & $2(2.9)$ & \\
\hline$>1000$ & $1(1.4)$ & $1(1.5)$ & \\
\hline CEA, ng/mL & $2.3 \pm 1.4$ & $2.1 \pm 1.7$ & 0.61 \\
\hline
\end{tabular}

BMI, body mass index; ASA, American Society of Anesthesiologists; AJCC, American Joint Committee on Cancer; CA 19-9, carbohydrate antigen 19-9; CEA, carcinoembryonic antigen.

Table 5. Comparative analysis of operative outcomes and complications for laparoscopic pancreaticoduodenectomy (LPD) and open pancreaticoduodenectomy (OPD) groups after propensity score matching.

\begin{tabular}{|c|c|c|c|}
\hline \multirow{2}{*}{ Characteristics } & Matched LPD & Matched OPD & $p$-Value \\
\hline & $(n=69)$ & $(n=69)$ & \\
\hline Operative time, $\min ($ mean $\pm \mathrm{SD})$ & $400.2 \pm 91.2$ & $344.6 \pm 80.9$ & $<0.001$ \\
\hline Transfusion, $n(\%)$ & & & 0.796 \\
\hline No & $60(87.0)$ & $59(85.5)$ & \\
\hline Yes & $9(13.0)$ & $10(14.5)$ & \\
\hline Number of harvested LN, $n$ (mean $\pm \mathrm{SD})$ & $14.2 \pm 5.9$ & $15.5 \pm 7.4$ & 0.261 \\
\hline Resection margin status, $n(\%)$ & & & $>0.999$ \\
\hline Negative (R0) & $68(98.5)$ & $68(98.5)$ & \\
\hline Positive (R1) & $1(1.5)$ & $1(1.5)$ & \\
\hline Length of hospital stay, days (mean \pm SD) & $13.7 \pm 10.8$ & $17.3 \pm 9.4$ & 0.048 \\
\hline $\begin{array}{l}\text { Number of postoperative painkiller } \\
\text { administrations (IV or IM), } n \text { (mean } \pm \text { SD) }\end{array}$ & $8.3 \pm 7.9$ & $11.1 \pm 7.5$ & 0.049 \\
\hline CR-POPF, $n(\%)$ & & & 0.029 \\
\hline No & $63(91.3)$ & $54(78.3)$ & \\
\hline Yes & $6(8.7)$ & $15(21.7)$ & \\
\hline
\end{tabular}


Table 5. Cont.

\begin{tabular}{|c|c|c|c|}
\hline \multirow{2}{*}{ Characteristics } & Matched LPD & Matched OPD & $p$-Value \\
\hline & $(n=69)$ & $(n=69)$ & \\
\hline Delayed gastric emptying, $n(\%)$ & & & 0.109 \\
\hline No & $65(94.2)$ & $59(85.5)$ & \\
\hline Yes & $4(5.8)$ & $10(14.5)$ & \\
\hline Complications, $n(\%)$ & & & 0.012 \\
\hline Grade 0-I & $58(84.1)$ & $45(65.2)$ & \\
\hline$\geq$ Grade II & $11(15.9)$ & $24(34.8)$ & \\
\hline Readmission due to complication, $n(\%)$ & & & 0.808 \\
\hline No & $60(87.0)$ & $61(88.4)$ & \\
\hline Yes & $9(13.0)$ & $8(11.6)$ & \\
\hline
\end{tabular}

SD, standard deviation; LN, lymph node; CR-POPF, clinically relevant postoperative pancreatic fistula.
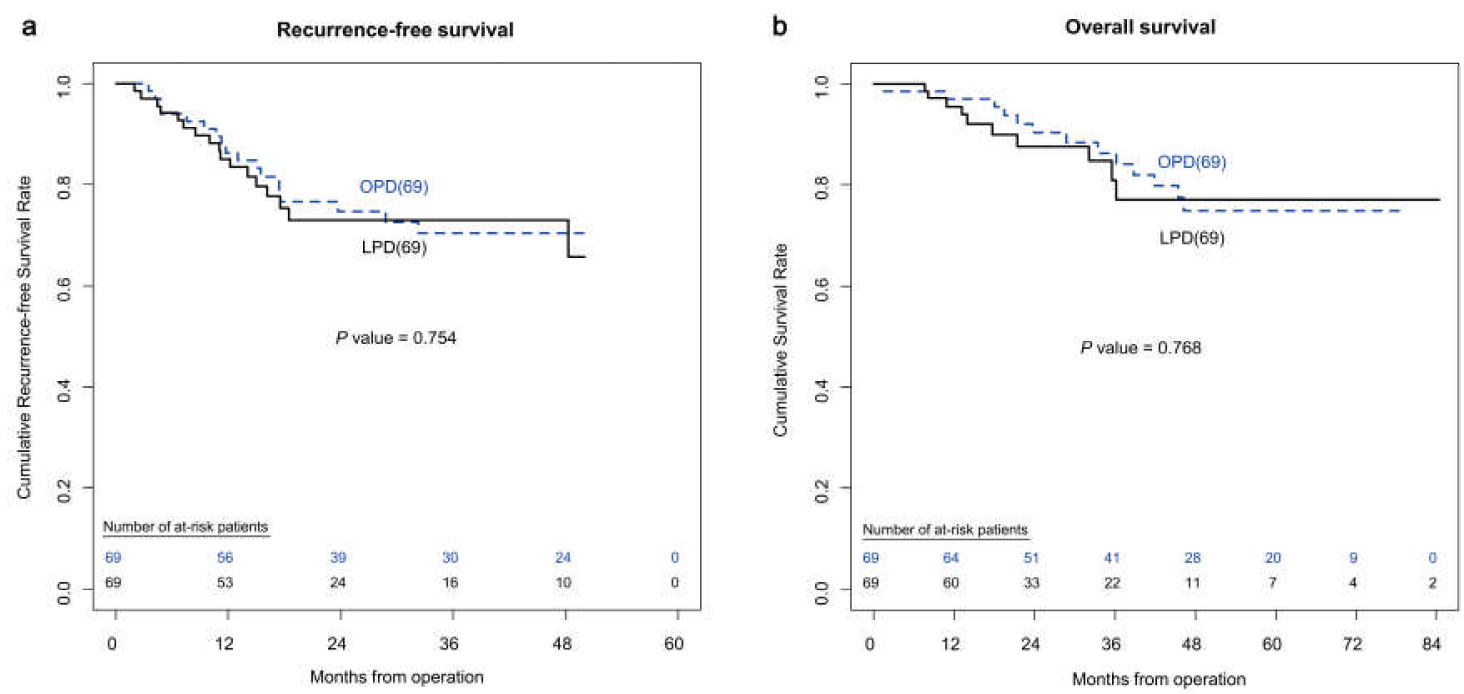

Figure 2. (a) Kaplan-Meier curves of recurrence free survival after surgery in propensity-score-matched patients who underwent OPD or LPD. (b) Kaplan-Meier curves of overall survival after surgery in propensity-score-matched patients who underwent OPD or LPD.

\section{Discussion}

"Periampullary cancer" is a nonspecific clinical term that refers to a variety of tumors, and AVC is distinct from other periampullary cancers in terms of presentation, molecular characteristics, and prognosis [28]. AVC is detected relatively early due to the appearance of jaundice and thus has a more favorable prognosis compared with other pancreaticobiliary malignancies and accounts for a large part of resectable periampullary cancers. AVC has been suggested as the most suitable for LPD among periampullary malignancies due to the relatively small size of tumors, lower possibility of vascular invasion, and higher resectability [15]. Because LPD represents a large proportion of periampullary cancers resected with PD and is suitable for LPD, it is essential to perform a comparative analysis of perioperative and oncologic outcomes between LPD and OPD in patients with AVC.

In the present study, we compared the perioperative outcomes, surrogate markers of predicting survival, and long-term survival outcomes between LPD and OPD groups in patients with AVC. We found that, compared with the OPD group, the LPD group had a higher proportion of indolent $\mathrm{T}$ stages and smaller proportion of perineural invasions. It is possible that surgeons may selectively include small, easily resectable tumors for LPD, thus presenting selection bias. Therefore, we conducted a propensity-score-matched analysis to minimize the influence of selection bias. After propensity score 
matching, there were no significant differences in the demographic and pathologic findings between the two groups.

PD involves multiple systems, and the complexity of performing three anastomoses can result in significant surgical trauma and subsequent risk of perioperative complications. Theoretically, surgical complications would be comparable between LPD and OPD because the two methods have the same resection area and reconstruction methods. However, many reports have shown that LPD is better in terms of postoperative recovery [9-12]. Likewise, our results showed improved overall morbidity, including CR-POPF, and shorter postoperative hospital stays in the LPD group. Palanivelu and colleagues performed a randomized controlled trial in patients with periampullary cancers to undergo either LPD or OPD and found that LPD resulted in shorter hospital stays [29]. We have previously reported the benefits of LPD in terms of postoperative pain, in comparison with OPD [4], in which the mean number of analgesic injections was significantly lower in the LPD group. Likewise, our current study also showed a similar result in patients with AVC in terms of the number of analgesic injections (8.3 vs. 11.1, $p=0.049$ ). The lower incidence of abdominal pain in LPD is believed to be closely related to early ambulation and recovery.

Pancreaticojejunostomy is the most critical procedure during PD, and POPF resulting from failure of pancreaticoenteric anastomosis is the most common complication following PD. In the present study, the LPD group had a lower incidence of CR-POPF than did the OPD group $(p=0.029)$. We suspect that the development of bowel wall edema would have contributed to the difference in the incidence of POPF between the two groups. Marjanovic et al. showed the beneficial effects of laparoscopic surgery versus open visceral surgery in preventing bowel wall edema [30] and concluded that prevention of bowel wall edema formation is an advantage of minimally invasive surgery with respect to anastomotic healing. Hiki et al. showed that postoperative inflammation is less pronounced after laparoscopic procedures than after open surgery [31]. Less manipulation and reduced exposure of the abdominal cavity in LPD could be the main factor of lower postoperative morbidity, compared with OPD. Postoperative immune function may also be affected by the degree of surgical trauma, such as the size of the abdominal wound and exposure of abdominal organs to air. Therefore, LPD is expected to result in less systemic immune response and abnormal release of inflammatory mediators, compared with conventional open approaches. These findings shed light on why our LPD group had fewer complications than the OPD group.

Long-term survival outcomes and surrogate markers predicting survival are crucial for evaluating surgical interventions in oncology. The present study was specifically designed for AVC, and propensity score matching analysis was used in order to conduct a meaningful comparison on the oncologic outcomes between LPD and OPD.

Appropriate lymphadenectomy is crucial because elimination of a sufficient quantity of lymph nodes is helpful for improving staging accuracy and regional tumor control. In addition, curative R0 resection is regarded as the most important factor for determining a better prognosis. In the present study, both groups had similar proportions of positive resection margin and retrieved lymph nodes, and there were no significant differences in recurrent-free survival and overall survival, either. Therefore, our results show that the range of oncologic resection determines the prognosis, regardless of the surgical approach.

Because this was a retrospective study, there is a possibility of selection bias, in which patients with better baseline health and relatively milder AVC disease status may have been chosen as candidates for LPD. Although we tried to minimize such selection bias by using propensity score matching analysis, a randomized controlled study will be helpful in drawing a more definitive conclusion.

\section{Conclusions}

In conclusion, LPD for AVC showed advantages over OPD in terms of less postoperative pain, lower incidence of postoperative complications, shorter hospital stays, and acceptable oncologic outcomes, including survival. Thus, we expect LPD to be more frequently applied in patients with AVC in the future. 
Author Contributions: Conceptualization, D.W.H., J.H.L., and W.L.; investigation, J.W.L., K.H., S.H., and D.S.; data curation, D.Y., J.K., Y.P., and E.J.; writing-original draft preparation, D.Y.; writing-review and editing, K.B.S.; supervision, S.C.K. All authors have read and agreed to the published version of the manuscript.

Funding: This research received no external funding.

Conflicts of Interest: The authors declare no conflict of interest.

\section{References}

1. Gaspar, B.; Beuran, M.; Paun, S.; Ganescu, R.; Hostiuc, S.; Negoi, I. Current strategies in the therapeutic approach for adenocarcinoma of the ampulla of Vater. J. Med. Life 2013, 6, 260-265. [PubMed]

2. Senatore, F.J.; Ynson, M.L.; Dasanu, C.A. Adenocarcinoma of the ampulla of Vater: What treatment options are available? J. Oncol. Pharm. Pract. 2015, 21, 364-369. [CrossRef] [PubMed]

3. Gagner, M.; Pomp, A. Laparoscopic pylorus-preserving pancreatoduodenectomy. Surg. Endosc. 1994, 8, 408-410. [CrossRef]

4. Song, K.B.; Kim, S.C.; Hwang, D.W.; Lee, J.H.; Lee, D.J.; Lee, J.W.; Park, K.M.; Lee, Y.J. Matched case-control analysis comparing laparoscopic and open pylorus-preserving pancreaticoduodenectomy in patients with periampullary tumors. Ann. Surg. 2015, 262, 146-155. [CrossRef] [PubMed]

5. Kim, S.C.; Song, K.B.; Jung, Y.S.; Kim, Y.H.; Park, D.H.; Lee, S.S.; Seo, D.W.; Lee, S.K.; Kim, M.H.; Park, K.M.; et al. Short-term clinical outcomes for 100 consecutive cases of laparoscopic pylorus-preserving pancreatoduodenectomy: Improvement with surgical experience. Surg. Endosc. 2013, 27, 95-103. [CrossRef]

6. De Rooij, T.; Lu, M.Z.; Steen, M.W.; Gerhards, M.F.; Dijkgraaf, M.G.; Busch, O.R.; Lips, D.J.; Festen, S.; Besselink, M.G. Minimally invasive versus open pancreatoduodenectomy: Systematic review and meta-analysis of comparative cohort and registry studies. Ann. Surg. 2016, 264, 257-267. [CrossRef]

7. Delitto, D.; Luckhurst, C.M.; Black, B.S.; Beck, J.L.; George, T.J., Jr.; Sarosi, G.A.; Thomas, R.M.; Trevino, J.G.; Behrns, K.E.; Hughes, S.J. Oncologic and perioperative outcomes following selective application of laparoscopic pancreaticoduodenectomy for periampullary malignancies. J. Gastrointest. Surg. 2016, 20, 1343-1349. [CrossRef]

8. Klompmaker, S.; van Hilst, J.; Wellner, U.F.; Busch, O.R.; Coratti, A.; D’Hondt, M.; Dokmak, S.; Festen, S.; Kerem, M.; Khatkov, I.; et al. Outcomes after minimally-invasive versus open pancreatoduodenectomy: A Pan-European propensity score matched study. Ann. Surg. 2020, 271, 356-363. [CrossRef]

9. Liao, C.H.; Wu, Y.T.; Liu, Y.Y.; Wang, S.Y.; Kang, S.C.; Yeh, C.N.; Yeh, T.S. Systemic review of the feasibility and advantage of minimally invasive pancreaticoduodenectomy. World J. Surg. 2016, 40, 1218-1225. [CrossRef]

10. Torphy, R.J.; Friedman, C.; Halpern, A.; Chapman, B.C.; Ahrendt, S.S.; McCarter, M.M.; Edil, B.H.; Schulick, R.D.; Gleisner, A. Comparing short-term and oncologic outcomes of minimally invasive versus open pancreaticoduodenectomy across low and high volume centers. Ann. Surg. 2019, 270, 1147-1155. [CrossRef]

11. Asbun, H.J.; Stauffer, J.A. Laparoscopic vs open pancreaticoduodenectomy: Overall outcomes and severity of complications using the Accordion Severity Grading System. J. Am. Coll. Surg. 2012, 215, 810-819. [CrossRef] [PubMed]

12. Kendrick, M.L.; Cusati, D. Total laparoscopic pancreaticoduodenectomy: Feasibility and outcome in an early experience. Arch. Surg. 2010, 145, 19-23. [CrossRef] [PubMed]

13. Croome, K.P.; Farnell, M.B.; Que, F.G.; Reid-Lombardo, K.M.; Truty, M.J.; Nagorney, D.M.; Kendrick, M.L. Total laparoscopic pancreaticoduodenectomy for pancreatic ductal adenocarcinoma: Oncologic advantages over open approaches? Ann. Surg. 2014, 260, 633-638. [CrossRef] [PubMed]

14. Adam, M.A.; Choudhury, K.; Dinan, M.A.; Reed, S.D.; Scheri, R.P.; Blazer, D.G., 3rd; Roman, S.A.; Sosa, J.A. Minimally invasive versus open pancreaticoduodenectomy for cancer: Practice patterns and short-term outcomes among 7061 patients. Ann. Surg. 2015, 262, 372-377. [CrossRef]

15. Chapman, B.C.; Gleisner, A.; Ibrahim-Zada, I.; Overbey, D.M.; Paniccia, A.; Meguid, C.; Brauer, B.; Gajdos, C.; McCarter, M.D.; Schulick, R.D.; et al. Laparoscopic pancreaticoduodenectomy: Changing the management of ampullary neoplasms. Surg. Endosc. 2018, 32, 915-922. [CrossRef]

16. Lu, B.; Cai, X.; Lu, W.; Huang, Y.; Jin, X. Laparoscopic pancreaticoduodenectomy to treat cancer of the ampulla of Vater. JSLS 2006, 10, 97-100. 
17. Owens, W.D.; Felts, J.A.; Spitznagel, E.L., Jr. ASA physical status classifications: A study of consistency of ratings. Anesthesiology 1978, 49, 239-243. [CrossRef]

18. American Joint Committee on Cancer. AJCC Cancer Staging Manual, 7th ed.; Springer: New York, NY, USA, 2010.

19. Bassi, C.; Marchegiani, G.; Dervenis, C.; Sarr, M.; Abu Hilal, M.; Adham, M.; Allen, P.; Andersson, R.; Asbun, H.J.; Besselink, M.G.; et al. The 2016 update of the International Study Group (ISGPS) definition and grading of postoperative pancreatic fistula: 11 years after. Surgery 2017, 161, 584-591. [CrossRef]

20. Dindo, D.; Clavien, P.A. What is a surgical complication? World J. Surg. 2008, 32, 939-941. [CrossRef]

21. Bonjer, H.J.; Hop, W.C.; Nelson, H.; Sargent, D.J.; Lacy, A.M.; Castells, A.; Guillou, P.J.; Thorpe, H.; Brown, J.; Delgado, S.; et al. Laparoscopically assisted vs open colectomy for colon cancer: A meta-analysis. Arch. Surg. 2007, 142, 298-303. [CrossRef]

22. Shin, S.H.; Kim, S.C.; Song, K.B.; Hwang, D.W.; Lee, J.H.; Lee, D.; Lee, J.W.; Jun, E.; Park, K.M.; Lee, Y.J. A comparative study of laparoscopic vs. open distal pancreatectomy for left-sided ductal adenocarcinoma: A propensity score-matched analysis. J. Am. Coll. Surg. 2015, 220, 177-185. [CrossRef]

23. Veldkamp, R.; Gholghesaei, M.; Bonjer, H.J.; Meijer, D.W.; Buunen, M.; Jeekel, J.; Anderberg, B.; Cuesta, M.A.; Cuschierl, A.; Fingerhut, A.; et al. Laparoscopic resection of colon cancer: Consensus of the European Association of Endoscopic Surgery (EAES). Surg. Endosc. 2004, 18, 1163-1185. [CrossRef]

24. Ferrone, C.R.; Finkelstein, D.M.; Thayer, S.P.; Muzikansky, A.; Fernandez-delCastillo, C.; Warshaw, A.L. Perioperative CA19-9 levels can predict stage and survival in patients with resectable pancreatic adenocarcinoma. J. Clin. Oncol. 2006, 24, 2897-2902. [CrossRef] [PubMed]

25. D'Agostino, R.B., Jr. Propensity score methods for bias reduction in the comparison of a treatment to a non-randomized control group. Stat. Med. 1998, 17, 2265-2281. [CrossRef]

26. Rosenbaum, P.R.; Rubin, D.B. The central role of the propensity score in observational studies for causal effects. Biometrika 1983, 70, 41-55. [CrossRef]

27. Austin, P.C. Some methods of propensity-score matching had superior performance to others: Results of an empirical investigation and Monte Carlo simulations. Biom. J. 2009, 51, 171-184. [CrossRef] [PubMed]

28. Sommerville, C.A.; Limongelli, P.; Pai, M.; Ahmad, R.; Stamp, G.; Habib, N.A.; Williamson, R.C.; Jiao, L.R. Survival analysis after pancreatic resection for ampullary and pancreatic head carcinoma: An analysis of clinicopathological factors. J. Surg. Oncol. 2009, 100, 651-656. [CrossRef] [PubMed]

29. Palanivelu, C.; Senthilnathan, P.; Sabnis, S.C.; Babu, N.S.; Srivatsan Gurumurthy, S.; Anand Vijai, N.; Nalankilli, V.P.; Praveen Raj, P.; Parthasarathy, R.; Rajapandian, S. Randomized clinical trial of laparoscopic versus open pancreatoduodenectomy for periampullary tumours. Br. J. Surg. 2017, 104, 1443-1450. [CrossRef]

30. Marjanovic, G.; Kuvendziska, J.; Holzner, P.A.; Glatz, T.; Sick, O.; Seifert, G.; Kulemann, B.; Kusters, S.; Fink, J.; Timme, S.; et al. A prospective clinical study evaluating the development of bowel wall edema during laparoscopic and open visceral surgery. J. Gastrointest. Surg. 2014, 18, 2149-2154. [CrossRef]

31. Hiki, N.; Shimizu, N.; Yamaguchi, H.; Imamura, K.; Kami, K.; Kubota, K.; Kaminishi, M. Manipulation of the small intestine as a cause of the increased inflammatory response after open compared with laparoscopic surgery. Br. J. Surg. 2006, 93, 195-204. [CrossRef]

(C) 2020 by the authors. Licensee MDPI, Basel, Switzerland. This article is an open access article distributed under the terms and conditions of the Creative Commons Attribution (CC BY) license (http://creativecommons.org/licenses/by/4.0/). 